\title{
Detection of Nosema spp. in worker bees, pollen and bee bread during the honey flow season
}

\author{
Rajmund Sokół, Maria Michalczyk \\ University of Warmia and Mazury, Faculty of Veterinary Medicine, \\ Department of Parasitology and Invasive Diseases, Olsztyn, Poland \\ Received September 21, 2015 \\ Accepted August 31,2016
}

\begin{abstract}
Nosema apis and Nosema ceranae are responsible for nosemosis in the honey bee (Apis mellifera). The aim of the study was to identify Nosema spp. during the honey flow season in bee colonies, for co-infection or no infection with Nosema apis/Nosema ceranae. Hive bees, forager bees, pollen grains brought by them, and bee bread were analysed. In the infected group, 12 of 30 samples of hive bees were infected with Nosema ceranae, 7 were co-infected, 3 were infected with Nosema apis. In samples of forager bees, 21 of 30 were co-infected, 8 were infected with Nosema ceranae. The analysis of pollen demonstrated that only 2 of 30 samples were infected with Nosema ceranae, 3 of 30 samples of bee bread were infected with Nosema ceranae, 3 were co-infected and 1 of 30 were infected with Nosema apis. In the uninfected group, 13 of 30 samples of hive bees were co-infected, 2 were infected with Nosema ceranae. In the forager bees group, 12 of 30 samples were co-infected, 2 were infected with Nosema ceranae. Only 1 pollen sample was infected with Nosema ceranae and 1 was co-infected, 2 of 30 samples of bee bread were co-infected, 2 were infected with Nosema ceranae. The study demonstrated that during the honey flow season, infection by microsporidian species occurs mainly in forager bees. Pollen and bee bread may be a source of spores mainly at the beginning of the honey flow season.
\end{abstract}

Apiology, coinfections, PCR

Nosema apis ( $N$. apis) and Nosema ceranae ( $N$. ceranae) are highly-specialised, parasitic unicellular eukaryotes from the division of Microsporidia (Adl et al. 2005). In the honey bee (Apis mellifera) they are responsible for nosemosis, considered one of the most common adult honey bee diseases in the world. Currently, most honey bees in Europe are infected with $N$. ceranae, which has also been reported from other regions of the world (Higes et al. 2006; Williams et al. 2008; Michalczyk et al. 2011; MartinHernandez et al. 2012). Bees become infected with the parasite microspores by ingesting water or pollen (Webster et al. 2004; Chen et al. 2008). Weather conditions during the honey flow season play an important role in the development of nosemosis. For N. apis, seasonality of the disease has been observed, while the prevalence of infections with $N$. ceranae remains on a similar level during the whole honey flow season (Higes et al. 2006, 2007; Paxton et al. 2007; Chen et al. 2009; Bourgeois et al. 2010; Forsgren and Fries 2010). The literature provides very limited data on the sources of bee infection with Nosema spp. spores or the routes of transmission. Pollen and bee bread have been indicated as potential sources of infection (Higes et al. 2008a). Disease in the apiary and bee colony is usually transmitted via combs infected with spores, water, and between insects by means of trophallaxis (OIE 2013).

The aim of our study was to identify Nosema spp. present during the honey flow season in infected (co-infected with $N$. apis/N. ceranae) and uninfected honey bee colonies. The analysis included 2 castes of worker bees: bees working on combs sampled directly from the central part of the nest, and foragers bringing pollen to the hive, as well as pollen grains collected by foragers and bee bread stored in newly built combs.

Address for correspondence:

Maria Michalczyk

Departament of Parasitology and Invasive Diseases

Faculty of Veterinary Medicine, University of Warmia and Mazury

Oczapowskiego 13 Street, 10-718 Olsztyn, Poland

http://actavet.vfu.cz/ 


\section{Materials and Methods}

Material for the study was sampled in March 2014 from a 50-hive apiary (5347’ , $\left.^{\circ} 20^{\circ} 30^{\prime} \mathrm{E}\right)$. A haemocytometric method (Neubauer chamber) was used to detect Nosema spp. spores in each honey bee colony by analysing 60 worker bees randomly sampled from winter hive debris. Multiplex polymerase chain reaction (PCR) demonstrated that $90 \%$ of positive samples were co-infected with $N$. apis/N. ceranae. Therefore, further tests were carried out on 5 honey bee colonies (group 1) without nosemosis symptoms, infected with Nosema spp. (more than $1.2 \times 10^{6}$ spores/worker bee), and with a co-infection confirmed by PCR ( N. apis/N. ceranae) and 5 bee colonies (group 2 - control) free from microsporidians. Every month from April to September 60 hive bees $(\mathrm{HB})$ were sampled randomly directly from honey combs in the central part of the nest, and 60 forager bees returning to the hive with pollen (FB) were sampled from the beehive entrance using a special tool. Multiplex PCR was used to separately analyse worker bees and pollen brought by them (Sokół and Michalczyk 2012). Pollen grains from forager bees were collected using sterile tweezers. A single sample contained 20 randomly collected pollen grains. In addition, about $5 \mathrm{~g}$ samples of bee bread stored in newly built marked combs were collected. Fifteen mg samples of bee bread were used for analysis. Deoxyribonucleic acid (DNA) was isolated from bees, pollen and bee bread using the same technique.

Genomic DNAwas isolated using the Genomic MiniA\&ABiotechnology kit(Gdynia, Poland) for DNAextraction by relying on genomic DNA's ability to bind to silica in the presence of high concentrations of chaotropic salts. The isolation process was carried out in accordance with the manufacturer's guidelines, and purified DNA was stored for further analyses in test tubes at a temperature of $-20^{\circ} \mathrm{C}$. The multiplex PCR assay involved the amplification of small subunit ribosomal ribonucleic acid (rRNA) sequences (16S rRNA) of Nosema apis and Nosema ceranae. The following primers were used: for $N$. ceranae - MITOC FOR (5'-CGGCGACGATGTGATATGAAAATATTAA-3') and MITOC REV (5'-CCCGGTCATTCTCAAACAAAAAACCG-3') amplifying a 218 bp product for $N$. apis and $321 \mathrm{bp}$ for $N$. ceranae (OIE 2013). Multiplex PCR analysis was carried out using the HotStarTaq Plus Polymerase (Qiagen, Germany) and the HotStarTaq Plus Master Mix Kit (Qiagen, Germany). The reaction mix of $20 \mu \mathrm{l}$ comprised around $120 \mathrm{ng}$ isolated DNA, $10 \mu \mathrm{l}$ HotStarTaq Plus Master Mix 2 times, $2 \mu \mathrm{l}$ CoralLoad Concentrate $\times 10$ and $0.1 \mu \mathrm{l}$ of each primer, supplemented with RNase-Free Water to $20 \mu 1$. Every reaction involved three controls: two positive controls with the DNA of Nosema apis and Nosema ceranae (Centro Nosema Apicola Regional, Dirección Genera de la Producción Agropecuaria, Consejería de Agricultura, Junta de Comunidades de Castilla-La Mancha, Spain) and one negative control where DNA was replaced with water. The reaction was carried out in the Eppendorf Mastercycler thermocycler. The PCR commenced with initial denaturation at $95{ }^{\circ} \mathrm{C}$ for $5 \mathrm{~min}$. The reaction mixture was then cycled $\times 35$ consisting of the following steps: denaturation at $94{ }^{\circ} \mathrm{C}$ for $45 \mathrm{~s}$, primer annealing at $55^{\circ} \mathrm{C}$ for $45 \mathrm{~s}$ and extension at $72{ }^{\circ} \mathrm{C}$ for 1 min. The last reaction was followed by final chain synthesis at $72{ }^{\circ} \mathrm{C}$ for $10 \mathrm{~min}$. The products of the multiplex PCR reaction were separated by electrophoresis in $2 \%$ agarose gel containing $0.5 \mu \mathrm{g} / \mathrm{ml}$ ethidium bromide for visualizing the resulting DNA fragments of Nosema spp. The size of the obtained products was evaluated by comparison with the GeneRuler ${ }^{\mathrm{TM}} 100$ bp 36 Ladder Plus (Fermentas, USA) molecular size marker. Electrophoresis results were archived using the GelDoc (Bio-Rad, USA) gel documentation system.

\section{Results}

The analysis carried out in April in honey bee colonies from group 1 (co-infection with $N$. apis/N. ceranae in winter hive debris) revealed that $2 \mathrm{HB}$ samples were co-infected ( N. apis/N. ceranae), two were infected with $N$. ceranae, and one was free from spores. In the same group, four FB samples were co-infected with $N$. apis/N. ceranae and one with $N$. ceranae. In May, all HB samples were infected with $N$. ceranae, and FB samples were co-infected ( $N$. apis/N. ceranae). In June, three HB samples were free from spores, and two were infected with $N$. apis. In May, four FB samples were co-infected, and one was infected with $N$. ceranae. In July, two HB samples were co-infected ( $N$. apis/ $N$. ceranae), two were infected with $N$. ceranae, and one was free from spores, while four FB samples were infected with $N$. ceranae and one was free from spores. In August, three HB samples were free from spores, one was infected with $N$. ceranae, and one was co-infected ( N. apis/N. ceranae), while three FB samples were co-infected (N. apis/N. ceranae), and two were infected with $N$. ceranae. In September, two HB samples were co-infected ( N. apis/N. ceranae), two were infected with $N$. ceranae, and one was infected with $N$. apis, while all FB samples were co-infected ( N. apis/N. ceranae) (Table 1).

The analysis of pollen collected from FB workers from group 1 across the study period revealed the presence of $N$. ceranae only in one sample taken in May and in one sample taken in June. 
Table 1. Detection of Nosema spp. in worker bees, pollen and bee bread in uninfected and infected colonies depending on the time of examination in individual colonies and months.

\begin{tabular}{|c|c|c|c|c|c|c|c|c|}
\hline \multirow{5}{*}{$\begin{array}{l}\text { Month of } \\
\text { examination/ } \\
\text { number of } \\
\text { colonies }\end{array}$} & \multicolumn{8}{|c|}{ Type of Nosema spp. } \\
\hline & \multicolumn{4}{|c|}{ Worker bees } & \multirow{2}{*}{\multicolumn{2}{|c|}{ Pollen (pollen grains) }} & \multirow{2}{*}{\multicolumn{2}{|c|}{ Bee bread }} \\
\hline & \multicolumn{2}{|c|}{ Hive bees HB } & \multicolumn{2}{|c|}{ Forager bees FB } & & & & \\
\hline & \multicolumn{8}{|c|}{ Group } \\
\hline & 1 & 2 & 1 & 2 & 1 & 2 & 1 & 2 \\
\hline \multicolumn{9}{|l|}{ April } \\
\hline \multirow[t]{5}{*}{$\mathrm{n}=5$} & $\mathrm{C}$ & - & $\mathrm{C}$ & - & - & - & $\mathrm{AC}$ & - \\
\hline & - & - & $\mathrm{AC}$ & - & - & - & $\mathrm{AC}$ & - \\
\hline & $\mathrm{C}$ & - & $\mathrm{AC}$ & - & - & - & $\mathrm{AC}$ & $\mathrm{AC}$ \\
\hline & $\mathrm{AC}$ & - & $\mathrm{AC}$ & - & - & - & - & - \\
\hline & $\mathrm{AC}$ & - & $\mathrm{AC}$ & - & - & - & - & $\mathrm{AC}$ \\
\hline \multicolumn{9}{|l|}{ May } \\
\hline \multirow[t]{5}{*}{$\mathrm{n}=5$} & $\mathrm{C}$ & $\mathrm{AC}$ & $\mathrm{AC}$ & - & - & - & - & - \\
\hline & $\mathrm{C}$ & - & $\mathrm{AC}$ & - & $\mathrm{C}$ & - & - & - \\
\hline & $\mathrm{C}$ & $\mathrm{AC}$ & $\mathrm{AC}$ & - & - & - & - & - \\
\hline & $\mathrm{C}$ & $\mathrm{AC}$ & $\mathrm{AC}$ & $\mathrm{AC}$ & - & - & $\mathrm{C}$ & - \\
\hline & $\mathrm{C}$ & $\mathrm{AC}$ & $\mathrm{AC}$ & $\mathrm{AC}$ & - & - & - & - \\
\hline \multicolumn{9}{|l|}{ June } \\
\hline \multirow[t]{5}{*}{$\mathrm{n}=5$} & A & - & $\mathrm{AC}$ & - & - & $\mathrm{AC}$ & - & $\mathrm{C}$ \\
\hline & - & $\mathrm{AC}$ & $\mathrm{AC}$ & $\mathrm{AC}$ & - & - & - & - \\
\hline & - & - & $\mathrm{C}$ & $\mathrm{C}$ & - & - & $\mathrm{C}$ & - \\
\hline & A & - & $\mathrm{AC}$ & - & - & - & $\mathrm{C}$ & - \\
\hline & - & $\mathrm{AC}$ & $\mathrm{AC}$ & $\mathrm{AC}$ & - & - & - & - \\
\hline \multicolumn{9}{|l|}{ July } \\
\hline \multirow[t]{5}{*}{$\mathrm{n}=5$} & - & - & $\mathrm{C}$ & $\mathrm{AC}$ & - & - & - & - \\
\hline & $\mathrm{AC}$ & $\mathrm{C}$ & $\mathrm{C}$ & - & - & - & - & - \\
\hline & $\mathrm{AC}$ & - & $\mathrm{C}$ & $\mathrm{AC}$ & - & $\mathrm{C}$ & - & - \\
\hline & $\mathrm{C}$ & - & - & - & $\mathrm{C}$ & - & - & - \\
\hline & $\mathrm{C}$ & $\mathrm{C}$ & $\mathrm{C}$ & - & - & - & - & - \\
\hline \multicolumn{9}{|l|}{ August } \\
\hline \multirow[t]{5}{*}{$\mathrm{n}=5$} & - & $\mathrm{AC}$ & $\mathrm{C}$ & $\mathrm{AC}$ & - & - & - & $\mathrm{C}$ \\
\hline & - & - & $\mathrm{AC}$ & $\mathrm{AC}$ & - & - & - & - \\
\hline & $\mathrm{AC}$ & - & $\mathrm{AC}$ & - & - & - & - & - \\
\hline & - & $\mathrm{AC}$ & $\mathrm{C}$ & $\mathrm{C}$ & - & - & - & - \\
\hline & $\mathrm{C}$ & - & $\mathrm{AC}$ & - & - & - & - & - \\
\hline \multicolumn{9}{|l|}{ September } \\
\hline \multirow[t]{5}{*}{$\mathrm{n}=5$} & $\mathrm{C}$ & $\mathrm{AC}$ & $\mathrm{AC}$ & $\mathrm{AC}$ & - & - & A & - \\
\hline & $\mathrm{AC}$ & $\mathrm{AC}$ & $\mathrm{AC}$ & $\mathrm{AC}$ & - & - & - & - \\
\hline & $\mathrm{AC}$ & $\mathrm{AC}$ & $\mathrm{AC}$ & $\mathrm{AC}$ & - & - & - & - \\
\hline & A & $\mathrm{AC}$ & $\mathrm{AC}$ & - & - & - & - & - \\
\hline & $\mathrm{C}$ & $\mathrm{AC}$ & $\mathrm{AC}$ & $\mathrm{AC}$ & - & - & - & - \\
\hline
\end{tabular}

A-infection with $N$. apis, $\mathrm{C}$ - infection with $N$. ceranae, $\mathrm{AC}-$ co-infection with $N$. apis and $N$. ceranae, -- no infection 
In April, three samples of bee bread were co-infected ( $N$. apis/N. ceranae). One sample taken in May and two samples taken in June were infected with $N$. ceranae. In July and August bee bread samples were free from spores, and one sample taken in September was infected with $N$. apis.

In group 2 (control, winter hive debris free from spores), all $\mathrm{HB}$ and $\mathrm{FB}$ samples taken in April were free from infection. In May, four HB samples were co-infected (N. apis/N. ceranae) and one was free from spores. Two FB samples were co-infected (N. apis/N. ceranae) and three were free from spores. In June, 2 HB samples were co-infected ( $N$. apis/N. ceranae) and three were free from spores, Two FB samples were co-infected ( $N$. apis/N. ceranae), two were free from spores and one was infected with $N$. ceranae. In July, two HB samples were infected with $N$. ceranae, three were free from spores, while two FB samples were co-infected ( $N$. apis/N. ceranae) and three samples were free from spores. In August, three HB samples were free from spores, two were co-infected ( $N$. apis $/ N$. ceranae), while two FB samples were co-infected ( N. apis/N. ceranae), two were free from spores, and one was infected with $N$. ceranae. In September, all HB samples were co-infected ( $N$. apis/N. ceranae), while four FB samples were co-infected ( $N$. apis/N. ceranae), and one was free from spores.

In group 2, only two samples of pollen taken from FB workers across the whole honey flow season were infected with Nosema spp., one sample collected in June was co-infected ( N. apis/N. ceranae), and one collected in July was infected with $N$. ceranae. The analysis of bee bread collected during the whole study period demonstrated infection with spores in four samples, co-infection (N. apis/N. ceranae) in two samples taken in April, and infection with $N$. ceranae in two samples taken in June and August (Table 1).

\section{Discussion}

To date, Nosema spp. microsporidians have been detected in honey bee colonies at different levels of their structure and in different periods of the honey flow season (Higes et al. 2008b). Our study was carried out in normally developing bee colonies free from pathogens other than nosema, including Varroa destructor. Despite the detection of Nosema spp. spores in individual months, no symptoms of nosemosis, e.g. diarrhoea or bee death, were observed in the analysed bee colonies. Nosema spores were more frequently detected in forager bees (FB) than in hive bees (HB). Other researchers also reported a high level of infection with spores in forager bees (Higes et al. 2008a; Meana et al. 2010; Botias et al. 2012; Smart and Sheppard 2012).

Higes et al. (2008a) explained the presence of Nosema spp. spores in pollen and bee bread by self-infection of foragers during pollen collection. Pollen may contain Nosema spp. spores, and foragers collecting it ad libitum may contribute to the spread of nosemosis (Hige s et al. 2008a; Pettis et al. 2012; Human et al. 2013; Williams et al. 2013). Pollen stored in comb cells in the form of bee bread, infected during foraging, may be a potential source of infection for new generations of bees (Martin-Hernandez et al. 2007; Higes et al. 2008a; Bourgeo is et al. 2010). Our study demonstrated the presence of Nosema spp. spores in 11 samples of bee bread and 4 samples of pollen. We demonstrated that pollen, but more frequently bee bread, may be a source of spores, particularly at the beginning of the honey flow season, when the demand for food to feed larvae is high.

Currently, molecular techniques are used to detect mild infections with microsporidians and to identify Nosema spp. by analysing a single insect or its body parts, e.g. salivary glands (Higes et al. 2008b; Human et al. 2013). The severity of infection depends on the microsporidian species. Our study demonstrated that mixed infection (co-infection) with $N$. apis/N. ceranae (45 samples) and infection with $N$. ceranae (25 samples), and with $N$. apis (5 samples) were the most frequent in the analysed bee colonies during the honey 
flow season. Recent studies indicated that infections with $N$. ceranae are more common in $A$. mellifera than infections with $N$. apis. Honey bees infected with this microsporidian species die promptly, usually outside the hive, without showing previous clinical symptoms (Higes et al. 2007; Paxton et al. 2007; Chen et al. 2009; Forsgren and Fries 2010). The presence of Nosema spores in worker bees from colonies may also be associated with subclinical symptoms of the disease, or result from recovery after infection in at least some worker bees. Collected food (honey, pollen, bee bread) or comb cells contaminated with spores by sick worker bees during comb cleaning may be a source of infection second to trophallaxis (Martin-Hernandez et al. 2007; Bourgeois et al. 2010). It can be assumed that Nosema spp. spores are permanently present in a honey bee colony, and microsporidians, depending on the environmental conditions and immune status of individual insects, cause either subclinical or fully-symptomatic infections in colonies. However, the mechanism underlying the infection of honey bees with different Nosema species has not been fully explained. On one hand, bees can be easily infected by ingesting food containing spores, but the progression of infection depends on the age of the insects. It is also important whether or not sick (infected) worker bees infect healthy individuals or larvae by trophallaxis, and at what time of the honey flow season this infection takes place. Undoubtedly, the progression of the disease is determined by the level of food intake in a single insect and the strength of a bee colony, i.e. its demand for food, or suggested contamination of worker bees with pesticides (Nozal et al. 2008; Alaux et al. 2010). Energetic stress may depopulate a honey bee colony, and impaired immunity can lead to fully-symptomatic nosemosis or promote the onset of other diseases (Campbell et al. 2010; Hedtke et al. 2011; Botias et al. 2013). It seems that pollen and probably water are more important epizootic sources of infection with Nosema spores, and the spread of the disease in a honey bee colony is promoted by trophallaxis and the hygiene-related behaviour of bees. However, infection can be transmitted from other castes of bees, including queens and drones (Czekońska 2000; Alaux N. ceranae et al. 2010; Traver and Fell 2011).

Pollen or bee bread are a potential source of infection Nosema spp. like workers bringing different products to the hive in the water.

\section{References}

Adl SM, Simpson AGB, Lane CE, Lukes J, Bass D, Bowser SS, Brown MW, Burki F, Dunthorn M, Hampl V, Heiss A, Hoppenrath M, Lara M, le Gall L, Lynn DH, McManus H, Mitchell EAD, Mozley-Stanridge SE, Parfrey LW, Pawlowski J, Rueckert S, Shadwick L, Schoch CL, Smirnov A, Spiegiel FW 2005: The new higher level classification of eukaorytes with emphasis on taxonomy of protists. J Eukayrot Microbiol 52: 399-451

Alaux C, Brunet JL, Dussaubat C, Mondet F, Tchamitchan S, Cousin M, Brillard J, Baldy A, Belzunces LP, Conte YL 2010: Interactions between Nosema microspores and a neonicotinoid weaken honeybees (Apis mellifera). Envion Microbiol 12: 774-782

Bourgeois AL, Rinderer TE, Beaman LD, Danka RD 2010: Genetic detection and quantification of Nosema apis and Nosema ceranae in honey bee. J Invertebr Pathol 103: 53-58

Botias C, Martín-Hernández R, Dias J, Garcia-Palencia P, Matabuena M, Juarranz A, Barrios L, Meana A, Nanetti A, Higes M 2012: The effect of induced queen replacement on Nosema spp. infection in honey bee (Apis mellifera iberiensis) colonies. Environ Microbiol 14: 845-859

Botias C, Martín-Hernández R, Barrios L, Meana A, Higes M 2013: Nosema spp. Infection and its negative effects on honey bees (Apis mellifera iberiensis) at the colony level. Vet Res 44: 1-14

Campbell J, Kessler B, Mayack C, Naug D 2010: Behavioural fever in infected honeybees: parasitic manipulation or coincidental benefit? Parasitology 137: 1487-1491

Chen Y, Evans JD, Smith BI, Pettis JS 2008: Nosema ceranae is a long-present and wide-spread microsporidian infection of the European honey bee (Apis mellifera) in the United States. J Invertebr Pathol 97: 186-188

Chen YP, Evans JD, Murphy C, Gutell R, Zuker M, Gundensen-Rindal D, Pettis JS 2009: Morphological, molecular, and phylogenetic characterization of Nosema ceranae, a microsporidian parasite isolated from the European honey bee, Apis mellifera. J Eukaryot Microbiol 56: 142-147

Czekońska K 2000: The influence of Nosema apis on young honeybee queens and transmission of the disease from queens to workers. Apidologie 31: 701-706 
Forsgren E, Fries I 2010: Comarative virulence of Nosema ceranae and Nosema apis in individual European honey bees. Vet Parasitol 170: 212-217

Hedtke K, Jensen PM, Jensen AB, Genersch E 2011: Evidence for emerging parasites and pathogens influencing outbreaks of stress-related diseases like chalkbrood. J Invert Pathol 108: 167-173

Higes M, Martin-Hernández R, Meana A 2006: Nosema ceranae, a new microsporidian parasite in honeybees in Europe. J Invertebr Pathol 92: 93-95

Higes M, Garcia-Palencia P, Martin-Hernández R, Aránzazu M 2007: Experimental infection of Apis mellifera honeybees with Nosema ceranae (Microsporidia). J Invertebr Pathol 94: 211-217

Higes M, Martín-Hernández M, Garrido-Bailón, García-Palencia P, Meana A 2008a: Detection of invective Nosema ceranae (Microsporidia) spores in corbicular pollen of forager honeybees. J Invertebr Pathol 97: 76-78

Higes M, Martin-Hernández R, Botías C, Garrido-Bailón E, González-Porto V, Barrios L, Jesús del Nozal M, Bernal JL, Jiménez JJ, Garcia-Palencia P, Meana A 2008b: How natural infection by Nosema ceranae causes honeybee colony collapse. Environ Microbiol 10: 2659-2669

Human H, Brodschneider R, Dietemann V, Dively G, Ellis JD, Forsgren E, Fries I, Hatjina F, Hu FL, Jaffè R, Jensen AB, Köhler A, Magyar J, Özikrim A, Pirk CWW, Rose R, Strauss U, Tanner G, Tarpy DR, van der Steen J, Vaudo A, Vejsnaes F, Wilde J, Williams GR, Zheng HQ 2013: Miscellaneous standard methods for Apis mellifera research. J Apic Res 52:1-55

Martín-Hernández R, Meana A, Prieto L, Martínez-Salvador A, Garrido-Bailón E, Higes M 2007: Outcome of colonization of Apis mellifera by Nosema ceranae. Apel Environ Microbiol 73: 6331-6338

Martín-Hernández R, Botías C, Garrido-Bailón E, Martínez-Salvador A, Prieto L, Meana A, Higes M 2012: Microsporidia infecting Apis mellifera coexistence or competition. Is Nosema ceranae replacing Nosema apis? Environ Microbiol 14: 2127-2138

Meana A, Martín-Hernández R, Higes M 2010: The reliability of spore counts to diagnose Nosema ceranae infections in honey bees. J Apic Res 49: 212-214

Michalczyk M, Sokół R, Szczerba-Turek A, Bancerz-Kisiel A 2011: A comparison of the effectiveness of the microscopic method and the multiplex PCR method in identifying and discriminating the species of Nosema spp. spores in worker bees (Apis mellifera) from winter hive debris. Pol J Vet Sci 14: 385-391

Nozal MJ, Berna JL, Martin MT, Bernal J, Alvaro A, Martin-Hernandez R, Higes M 2008: Trace analysis of fumagilin in honey by liquid chromatography -DAD- electrospray ionization mass spectrometry. J Chromatogr A 1190: 224-231

OIE: Manual for Terrestrial Animals 2013: Chapter 2.2.4.: Nosemosis of honeybees www document URL http://www.oie.int/international-standard-setting/terrestrial-manual/access-online/

Paxton R, Klee J, Korpela S, Fries I 2007: Nosema ceranae has infected Apis mellifera in Europe since at least 1998 and may be more virulent than Nosema apis. Apidologie 38: 558-565

Pettis JS, Vanengelsdorp D, Johnson J, Dively G 2012: Pesticide exposure in honey bees results in increased levels of the gut pathogen Nosema. Naturwissenschaften 99: 153-158

Smart MD, Sheppard WS 2012: Nosema ceranae in age cohorts of the western honey bee. J Invertebr Pathol 109: 148-151

Sokół R, Michalczyk M 2012: Detection of Nosema spp. in worker bees of different ages during the flow season. J. Apicult. Sci. 56: 19-25

Traver BE, Fell RD 2011: Nosema ceranae in drone honey bees (Apis mellifera). J Invert Pathol 109: 187-193

Webster TC, Pomper KW, Hunti G, Thacker EM, Jones SC 2004: Nosema apis infection in worker and queen Apis mellifera. Apidologie 35: 49-54

Williams GR, Shafer ABA, Rogers REL, Shutler D, Stewart DT 2008: First detection of Nosema ceranae, a microsporidian parasite of European honey bees (Apis mellifera), in Canada and central USA. J Invertebr Pathol 97: 189-192

Williams GR, Alaux C, Costa C, Csáki T, Dublet V, Eisenhardt D, Fries I, Kuhn R, McMahon D, Medrzycki P, Murray TE, Natsopoulou ME, Neumann P, Oliver R, Paxton RJ, Pernal SF, Shutler D, Tanner G, van der Steen JJM, Brodschneider R 2013: Standard methods for maintaining adult Apis mellifera in cages under in vitro laboratory conditions. J Apic Res 52: 1-35 